\title{
THE DEVELOPMENT OF A MODEL-ALGORITHM FOR PREDICTING HAILSTORMS IN CENTRAL MACEDONIA, GREECE
}

DOI: http://dx.doi.org/10.18509/GBP.2018.07

UDC: 551.501:551.578.7(495)

\author{
Tzeni Antoniou \\ Theodore Karacostas \\ Department of Meteorology and Climatology, Aristotle University of Thessaloniki, Greece
}

\begin{abstract}
The objective on this study is to create a model-algorithm, in order to predict-forecast hailstorms in the area of central Macedonia-Greece, where the Greek National Hail Suppression Program is conducted. The examined time period is from April to September, for the years 2008, 2009 and 2010. The data used were obtained from the C-band weather radar being located next to the area of interest, weather charts and the daily atmospheric soundings, being launched at the synoptic station of Thessaloniki and analyzed from the University of Wyoming, USA.

The adopted methodology relies upon the weighted and nonlinear multiple regression analysis theory, where certain functions of the correlation values between the dependent variable and each one of the independent variables, were used for the determination of the weighted coefficients. As dependent variable was used the observed -by the weather radar- daily maximum reflectivity values. On the other hand, eight (8) independent variables were chosen, through the statistical analyses of twenty-six (26) instability, microphysical and thermodynamic parameters, in order to form a stable, nonlinear, model-algorithm. In general, the adopted independent variables describe the thermodynamic and dynamic characteristics, together with instability factors and the precipitable water, of the encountered hailstorms.

The algorithm was developed based upon the exploratory set of data information and it was statistically evaluated by using the confirmatory set of data. The evaluation procedure proved that the developed nonlinear model-algorithm is a reliable and useful tool of predicting and forecasting hailstorm activity in the examined area of Central Macedonia, Greece.
\end{abstract}

Keywords: hailstorms; regression analysis; nonlinear algorithm; radar reflectivity; Central Macedonia.

\section{INTRODUCTION}

The phenomenon of hailstorms has been investigated by several scientists due to its complexity and difficulty, particularly in prediction and also because of the catastrophic damages it can create. In Greece, especially in summertime, hail appears to be one of the most common natural disasters, affecting agriculture, livestock and generally human activities.

Hence, the objective on this study is to develop a model-algorithm, in order to predictforecast hailstorms in the area of central Macedonia-Greece, where the Greek National Hail Suppression Program is conducted. To meet this objective, the most appropriate meteorological parameters have been chosen in order to thoroughly and scientifically 
describe the phenomenon under consideration. Somehow similar studies have been performed in the near present by Tournaviti (1999) [1], Stolaki (2004) [2], Dimoutsi (2005) [3] and Sfiri (2012) [4].

\section{DATA AND METHODOLOGY}

The aim of predicting hailstorms was based on the existence of the Greek National Hail Suppression Program (NHSP). This program is weather modification project, being applied on the area of Central Macedonia (Greece), with the objective to minimize and suppresses the hail damages over the protected area, which is depicted in Figure 1. The data information used on this study correspond to the protected area, being obtained from the operational C-band weather radar, which is located just next to the area of interest and from the daily atmospheric soundings (12UTC), being launched at the synoptic station of Thessaloniki and fully analyzed from the University of Wyoming, USA.

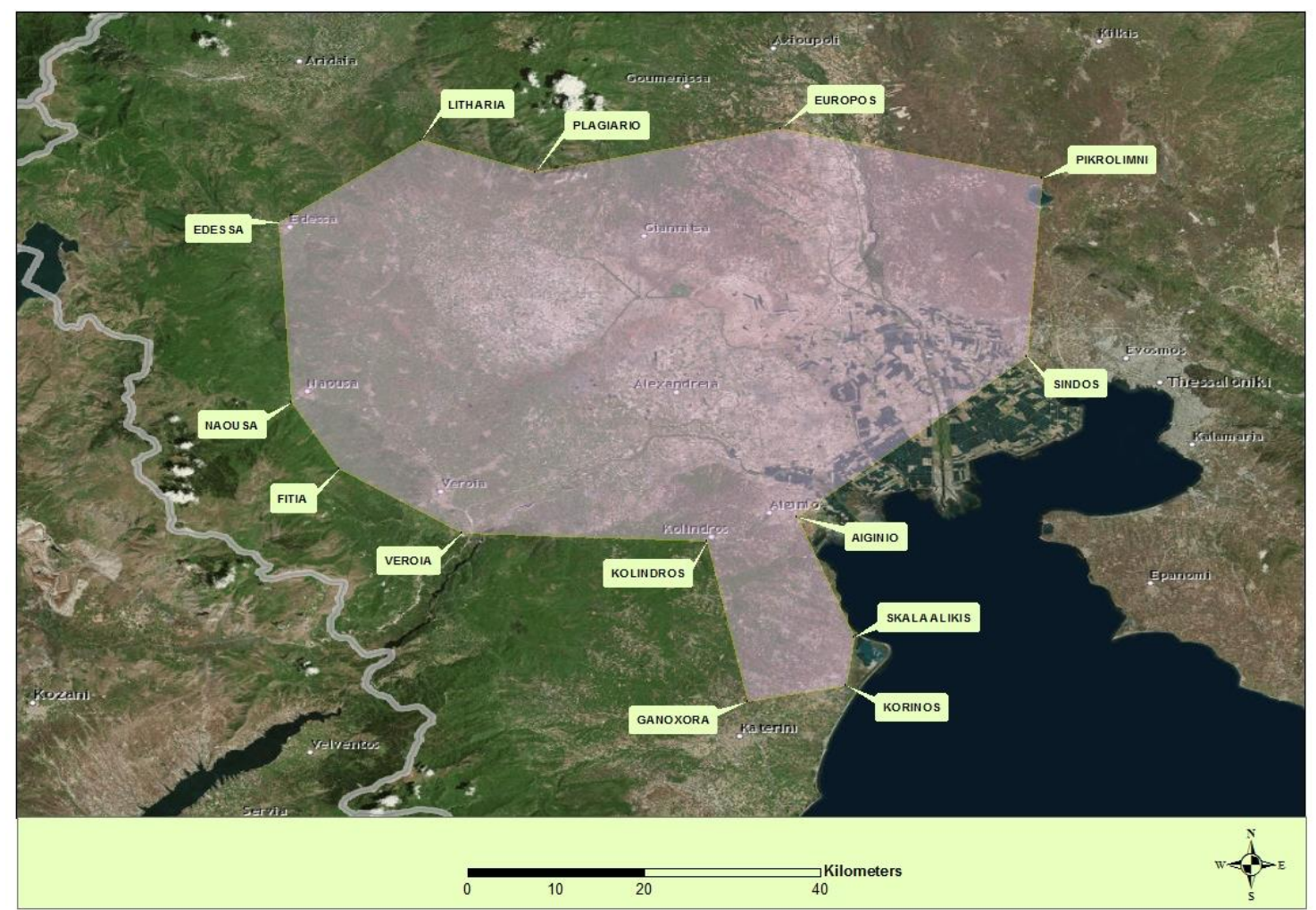

Figure 1: The operational are of the Greek National Hail Suppression Program (NHSP) in Central Macedonia (Greece).

Hailstorms are commonly observed in summer time for the examined area. Consequently, the Greek NHSP is mainly operational from 1 April to 30 September each year. According to this, the study period of this research incorporates the hail days from the month-period April to September for the three years: 2008, 2009 and 2010. Hence, the total number of the encountered hail days (hail on the ground) reached the number of 256 (total period). The radar and sounding data information were carefully checked about their correctness and their compatibility with actual measurements and weather conditions for each one of the hail days. The identified "outliers" were deleted and did not used to any further processing. As a result, a $4.3 \%$ of the initial data information was rejected. Furthermore, fifty (50) hail days were "a priori" extracted through a random number generator 
procedure, in order to consist the confirmatory period, which would be used for the evaluation and confirmation of the derived model-algorithm. The actual model-algorithm will be developed based upon all the rest hail days, which consist the exploratory period. The methodology applied for the development of the model-algorithm is based on the nonlinear multiple regression analysis procedure. The model-algorithm consists of a dependent variable, which mainly indicates the hail existence with a preferable signification of the hail intensity-severity and a number of independent variables, with high physical meaning and statistical influence to the examined phenomenon. Based upon international (Browning, 1977) [5] and national (Karacostas, 1984) [6] literature, the best fitted parameter could be considered the radar maximum reflectivity value, which is a very good indicator for hail existence and of hail intensity-severity. Browning (1977) [5] and Karacostas (1984) [6] adopted the threshold radar reflectivity value of more than $45 \mathrm{dbz}$ and $35 \mathrm{dBz}$, respectively. The maximum reflectivity value has been used as the dependent variable for the development of the indices: FK by Floca and Karacostas (1988) [7], TK-4 by Karacostas (1990) [8] and THE by Chatzi (1992) [9].

This particular model-algorithm was developed based upon the syntheses of linear and nonlinear regression analyses procedures between the maximum reflectivity and each one of the independent variables. The independent variables were chosen among thirty (30) meteorological parameters, which were evaluated and chosen according to their physical and statistical relationship with the dependent variable. All of them are directly or indirectly contribute to the hailstorm and hail formation and reinforcement procedures and they are theoretically associated with the existent atmospheric instability, the available humidity and important thermodynamic and microphysical parameters.

As a first step, the correlation matrix of all the independent variables was calculated. According to the resulting correlation coefficients, the highly inter-correlated independent variables, which exhibit similar physical meanings, were excluded from the development procedure of the model-algorithm.

Hence, a correlation matrix between each one of the remaining independent variablesparameters and the dependent variable was calculated. Taking into consideration, firstly the meteorological criteria and the physical meaning of the independent variables with respect to the potentiality of hail formation, together with the encountered high correlation coefficient $(\mathrm{R})$ values of them with the dependent variable of maximum reflectivity, the model-algorithm was developed. Linear and nonlinear relationships between the selected independent variables with the dependent variables were statistically synthesized to form the final mathematical expression of the model-algorithm.

Therefore, the model-algorithm was resulted from the sums of both linear and nonlinear equations (polynomial), according to the best fit of the independent variable to the maximum reflectivity. This multiple regression model-algorithm is mathematically expressed through equation (1).

$$
\begin{aligned}
\max d B z=w_{i} & \left(a_{i}+b_{i} X_{i}\right)+\sum_{1}^{4} w_{i}\left(a_{i}+b_{i} X_{i}+c_{i} X_{i}^{2}\right) \\
& +\sum_{1}^{2} w_{i}\left(a_{i}+b_{i} X_{i}+c_{i} X_{i}^{2}+d_{i} X_{i}^{2}+d_{i} X_{i}^{3}\right)+w_{i}\left(a_{i}+b_{i} X_{i}+c_{i} X_{i}^{2}\right. \\
& \left.+d_{i} X_{i}^{3}+e_{i} X_{i}^{4}\right)
\end{aligned}
$$


The maxdBz stands for estimated maximum reflectivity, $\mathrm{X}_{\mathrm{i}}$ stands for the i selected independent variables and $a_{i}, b_{i}, c_{i}, d_{i}, e_{i}$ are the estimated constants.

It is worth mentioning that the $\mathrm{w}_{\mathrm{i}}$ constitute the weighted coefficients, which are calculated through equation (2), contributing meteorologically quite a lot to the physical meaning of the model-algorithm. Where $\mathrm{R}_{\mathrm{i}}$ is the correlation coefficient for the $\mathrm{i}$ selected independent variable.

$$
w_{i}=\frac{R_{i}}{\sum R}
$$

\section{RESULTS}

In the present study the independent variables-parameters were related to atmospheric pressure, geopotential height, air temperatures, mixing ratios, relative humidity and the height of specific temperatures encountered in different atmospheric layers. From the initial thirty (30) parameters, four (4) of them were initially rejected due to missing appropriate measurements.

Eight (8) of the remaining twenty-six (26) meteorological parameters were selected for the development of the model-algorithm, since they appeared the most relevant to the studied phenomenon.

Three of these eight parameters were instability indices, two had to do with the humidity of the atmosphere and the other three were microphysical parameters. Specifically, the independent variables-parameters were: mixing ratio at the surface (MRSUR), precipitable water (PWAT), potential temperature of the mean mixing layer (MLTH), Showalter index (SHOW), Lifted index (LIFT), K index (KINX), height of the $-5^{\circ} \mathrm{C}$ isothermal ( $\left.\mathrm{H}_{-5}\right)$ and relative humidity at surface (RHSUR). The aforementioned parameters and their coefficients of determination and correlation coefficients, with maximum reflectivity values, are depicted in Table 1.

Table 1: Coefficients of determination and correlation coefficients between the eight independent variables and maximum reflectivity values.

\begin{tabular}{|l|l|c|c|}
\hline \multicolumn{1}{|c|}{ INDEPENDENT VARIABLES } & & \multicolumn{1}{c|}{$\mathbf{R}^{\mathbf{2}}$} & R \\
\hline Mixing ratio at surface & MRSUR & 0.40 & 0.64 \\
\hline Precipitable water & PWAT & 0.34 & 0.58 \\
\hline Potential temperature of the mean mixing layer & MLTH & 0.31 & 0.56 \\
\hline Showalter index & SHOW & 0.23 & 0.48 \\
\hline Lifted index & LIFT & 0.18 & 0.42 \\
\hline K index & KINX & 0.17 & 0.41 \\
\hline Height of -5 ${ }^{\circ}$ isothermal & H.5 & 0.15 & 0.39 \\
\hline Relative humidity at surface & RHSUR & 0.09 & 0.30 \\
\hline
\end{tabular}

It should be stated that most of these parameters have been frequently chosen to form similar model-algorithms by many other investigators who studied hailstorms over the same or similar area.

With the objective to incorporate the best fitted regression equation between maximum reflectivity and each one of the eight meteorological parameters, the equations tested were: linear, logarithmic, exponential, hyperbolic and $2^{\text {nd }}, 3^{\text {rd }}$ and $4^{\text {th }}$ grade polynomial. The Showalter index was the only parameter which revealed linear regression equation 
with the maximum reflectivity. The seven remaining parameters, as they were mentioned in Table 1 (MRSUR, PWAT, MLTH, LIFT, KINX, H-5, RHSUR), used $2^{\text {nd }}$ grade polynomial, $3^{\text {rd }}$ grade polynomial, $2^{\text {nd }}$ grade polynomial, $2^{\text {nd }}$ grade polynomial, $4^{\text {th }}$ grade polynomial, $2^{\text {nd }}$ grade polynomial and $3^{\text {rd }}$ grade polynomial, respectively. The weighted coefficients were calculated based on the correlation coefficients of these linear and nonlinear equations between the dependent variable and the independent ones and they are presented in Table 2.

Table 2: The calculated weighted coefficients between the independent variables and maximum reflectivity.

\begin{tabular}{|l|l|l|l|l|l|l|l|}
\hline MRSUR & PWAT & MLTH & SHOW & H$_{-5}$ & LIFT & KINX & RHSUR \\
\hline 0.1686 & 0.1546 & 0.1473 & 0.1270 & 0.1029 & 0.1126 & 0.1084 & 0.0786 \\
\hline
\end{tabular}

Taking into consideration all these theoretical and practical methodologies and procedures, together with all the calculations performed, the final developed mathematical expression of the model-algorithm is demonstrated through the equation (3).

$$
\begin{aligned}
& \text { maxdBz }=-0.027 \text { MRSUR }^{2}+0.844 \text { MRSUR }+0.00022 \text { PWAT }^{3}-0.012 \text { PWAT }^{2}+ \\
& +0.642 \text { PWAT }-0.0129 \text { LTH }^{2}+7.686 \text { MLTH }-0.147 \text { SHOW }+7.2 * 10^{-6}\left(\boldsymbol{H}_{-5}\right)^{2}- \\
& -0.0129(\boldsymbol{H}-5)-0.0002 \text { LIFT }^{4}+0.0042 \text { LIFT }^{3}-0.0058 \text { LIFT }^{2}-0.1856 \text { LIFT }+ \\
& +0.00138 \boldsymbol{K I N X}^{2}-0.0219 \mathrm{KINX}-7.9 * 10^{-6} \boldsymbol{R} \boldsymbol{H S U R} \boldsymbol{R}^{3}+ \\
& +0.0015 \text { RHSUR }^{2}-0.0688 \text { RHSUR }-1093.56
\end{aligned}
$$

This final mathematical expression of the model-algorithm was resulted by using the $80 \%$ of the available data information, which correspond to the exploratory period. Investigating the representativeness, objectivity and reliability of the model-algorithm, Equation (3), was also applied to the analogous data information which correspond to the confirmatory period. The resulted predicted values were then compared to the actual observed maximum daily reflectivity values, in order to demonstrate the model's ability to correctly predict-estimate the hailstorm occurrence. Figure 2 depicts these comparisons, obtained through the linear regression procedure, for the exploratory (top), confirmatory (middle) and the whole examined period (bottom). According to these comparisons between the predicted and the observed daily maximum reflectivity values, the encountered correlation coefficients $(R)$ reached to the levels of: $R=0.6872$ for the exploratory period, $\mathrm{R}=0.7661$ for the confirmatory period and $\mathrm{R}=0.6976$ for the whole period.

It is believed that this established model-algorithm is a quite acceptable, reliable and very useful tool for the prediction of an extreme event, such as, hailstorm. 

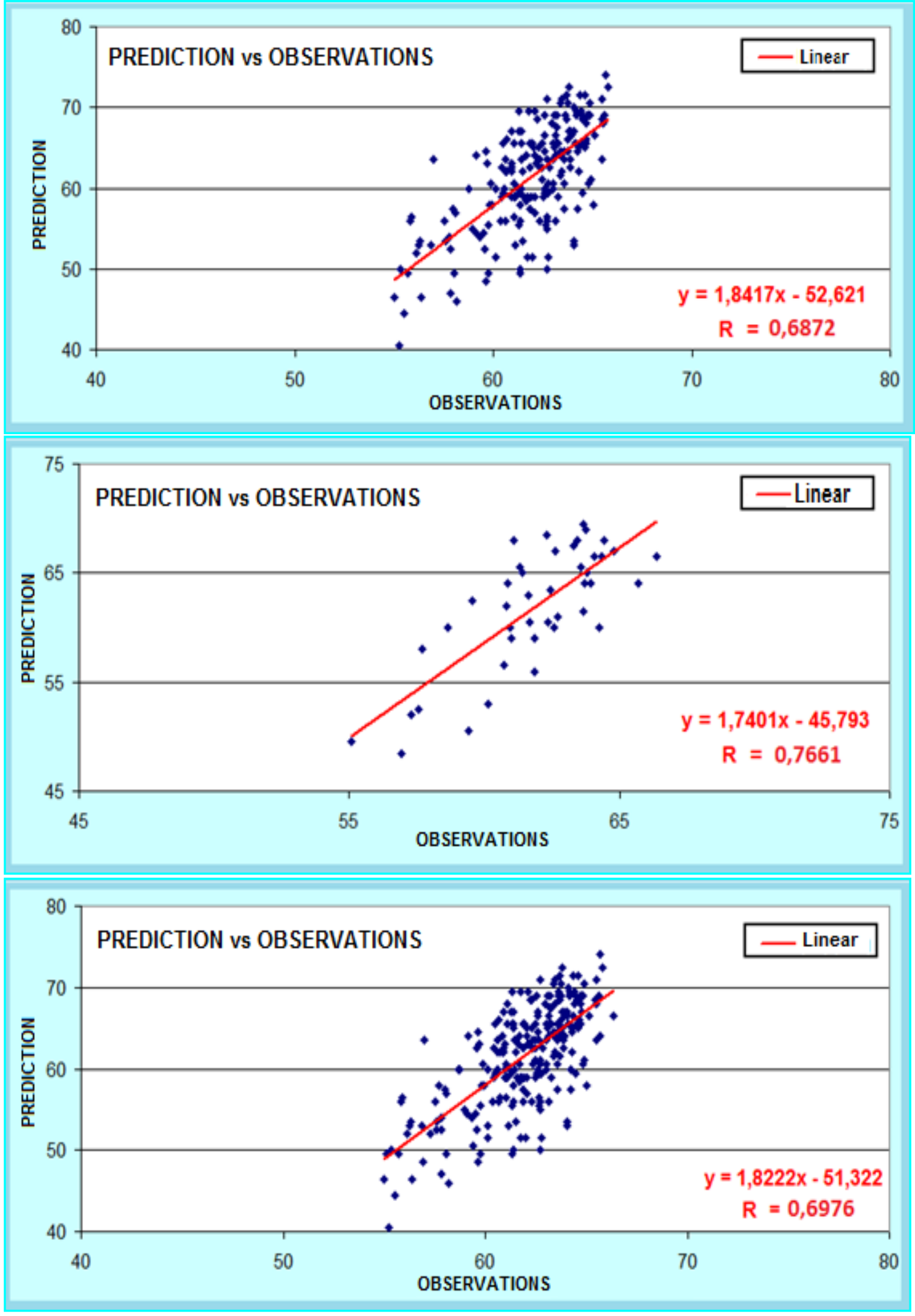

Figure 2: Comparison between the predicted by the developed model-algorithm values and the observed daily maximum reflectivity values for the exploratory (top), the confirmatory (middle) and the whole period (bottom). 


\section{CONCLUSIONS}

Using data information from daily atmospheric soundings and a weather radar, a modelalgorithm was developed for predicting hailstorms over the area of Central Macedonia. The dependent variable was chosen to be the daily maximum reflectivity measured from a C-band weather radar. The parameters used as the independent variables of the modelalgorithm were selected based upon the use of meteorological criteria and statistical methods. The model-algorithm was developed based mostly on nonlinear multiple regression analyses.

The chosen independent variables used for the development of the model-algorithm are the following: mixing ratio at the surface (MRSUR), precipitable water (PWAT), potential temperature of the mean mixing layer (MLTH), Showalter index (SHOW), Lifted index (LIFT), $\mathrm{K}$ index (KINX), height of the $-5^{\circ} \mathrm{C}$ isothermal $\left(\mathrm{H}_{-5}\right)$ and relative humidity at surface (RHSUR). Moreover, each one of the selected independent variables, indirectly contributed to the model-algorithm through the calculation procedure of their equivalent weighted coefficients.

The comparisons of the predicted by the model-algorithm values against the observed ones demonstrated the very acceptable linear correlation coefficients values of 0.6872 , 0.7661 and 0.6976 , for the exploratory, confirmatory and the whole examined period, respectively. Hence, it is concluded that the developed model-algorithm is a very acceptable, reliable and particularly useful tool for the prediction of the extreme event of hailstorm over the area of Central Macedonia, Greece.

\section{REFERENCES}

[1] Tournaviti, A. N., 1999: Contribution to the study of hailstorm forecasting over the northern Greek area. M.Sc. Thesis, Dept. of Meteorology and Climatology. Aristotle University of Thessaloniki, Greece. [in Greek]

[2] Stolaki S. N., 2004: On the study of hailstorm characteristics over Hmathia-Pella area and their projective estimations during the $21^{\text {st }}$ century. M.Sc. Thesis, Dept. of Meteorology and Climatology. Aristotle University of Thessaloniki, Greece. [in Greek]

[3] Dimoutsi, S., 2005: The jet-stream and its effect to the hailstorms over the central Macedonian area. M.Sc. Thesis, Dept. of Meteorology and Climatology. Aristotle University of Thessaloniki, Greece. [in Greek]

[4] Sfiri, E. E., 2012: Hailstorm studies over the Hmathia-Pella area. M.Sc. Thesis, Dept. of Meteorology and Climatology. Aristotle University of Thessaloniki, Greece. [in Greek]

[5] Browning, K. A., 1977: The structure and mechanics of hailstorms. In "Hail: A review of hail science and hail suppression", G. B. Foote and C. A. Knight, (Eds), Meteor. Monogr., 16, No. 38, pp 1-43.

[6] Karacostas, T. S., 1984: The design of the Greek Hail Suppression Program, Ninth Conf. on Weather Modification, Amer. Meteor. Soc., Park City, Utah, U.S.A., 26-27.

[7] Floca, E. and Karacostas, 1988: On the contribution of convective storm forecasting over the northern Greek area. Meteorologika, No. 73, $\sigma \varepsilon \lambda . ~ 229-238$. [in Greek]

[8] Karacostas, T. S., 1990: The development of an index as an aid in forecasting mesoscale convective storms over North-Central Greece. 21st International Conference for Alpine Meteorology, Engelberg, Switzerland, pp. 227-230.

[9] Chatzi, E., 1992: Development of a forecast instability index over the Central Macedonia area. Proc. $1^{\text {st }}$ Greek Conf. on Meteorology, Climatology and Atmospheric Physics. Thessaloniki, Greece, pp 423-430. 